\title{
Women and the Environment: Ecofeministic Approach to Environmental Attitudes and Behavior in Iran
}

Fahimeh Hosseinnezhad ${ }^{1 *}$

${ }^{1}$ Hacettepe University, TURKEY

*Corresponding Author: hosseinnejad64@gmail.com

Citation: Hosseinnezhad, F. (2017) Women and the Environment: Ecofeministic Approach to Environmental Attitudes and Behavior in Iran, European Journal of Sustainable Development Research, 1:1 (2017), 4.

doi: http://dx.doi.org/10.20897/ejosdr.201704

Received: May 13, 2016; Accepted: August 20, 2016; Published: January 17, 2017

\begin{abstract}
In the contemporary world industry, urbanization, and capitalism have destroyed the environment on such a large-scale that to solve this problem would require expensive and long-term treatments. Public participation is a low-cost way to address these issues. Women are able to protect the environment because some of the environment's problems begin from the home. The current research is using the survey based on quantitative research method to investigate the theory of ecofeminism, the attitudes and behaviors of women and men regarding the environment. Data collected thorugh questionnaire and multiple choice questions. Results of this study show that women pay more attention to the environment. Efficient consumption of energy, use of public transport, waste separation, reuse of certain goods, and the avoidance of waste dumping in the environment are significant for women, but men show little interest in these behaviors. Women are more supportive of the environment than men are.
\end{abstract}

Keywords: ecofeminism, environment, behavior, attitude

\section{INTRODUCTION}

Research on women and their view of the world has a major position in the humanities and social sciences. The starting point of the feminist approach is the basic question of what do we know of women. The participation of women in social, cultural, economic, educational, political, and environmental issues is essential and is a standard of socioeconomic and sustainable development. Emerging environmental problems strengthen the idea that the environment is a public matter, and its protection is the obligation of all humans, although 'some feminists believe the environment to be a feminine subject' (Warren, 1991).

In 1974 the term of "eco-feminism" was introduced by French Feminist d'Eaubonne as a fundamental link between ecology and women's studies that was the combination of environmental consideration, feminist and the feminine spirit (Brammer, 1998). Ecofeminism looks at cultural and social concerns dealing with the relationship that the oppression of women has with the degradation of nature. Oppression of women and the environment has been "twin subordinations" rising some 5000 years ago with the emergence of Western patriarchy. Patriarchy was based on Dualism a concept that separates the body from the mind, male from the females, human from nature (Salman, 2007).

This paper aims to investigate the attitudes and behaviors of women and men towards the environment, according to the theory of ecofeminism. Ecofeminism is a theoretical link between feminists and environmentalists that emphasizes the role of women in environmental protection. 
There was some limitation on this study. Considering the fact that current study was performed from an environmental sociologic perspective in Iran for the first time, there was no model in the research background. Therefore, conceptionalization of the environmental behavior in the context of Iran was difficult. Consequently, variables and questions of research were examined and consulted with experts on frequent occasions. In the present study, there was also scaling limitations. Translating NEP scale that developed by Dunlap and Van Liere to Persian was very challenging. To solve this problem, we did a reverse translation; since estimate validity and reliability of questionnaire was dependent to an accurate translation in the first place.

\section{Ecofeminism Theory}

Up until the idea of the inequality between men and women and the subservience of women to men as natural, something given and beyond human powers to alter was a taken-for-granted perspective. Women were held to be physically and psychologically weaker than men and seen as occupying a position somewhere below man but above animals or nature. It is this historical and conceptual connection between women and nature that makes the adoption of a gendered approach to the discussion of social theory and the environment not just interesting but absolutely essential (Barry, 1999).

For ecofeminists, it is the obvious fact that patriarchal culture has located women somewhere between men and the rest of nature on a conceptual hierarchy of being. This has enabled ecofeminists to identify what they see as a similar logic of domination between the destruction of nonhuman and the oppression of women. Indeed, it is a central claim of many ecofeminists that the larger culture's devaluation of natural processes was a product of masculine consciousness. As Simone de Beauvoir observed in her wide ranging exploration of the "second sex" women as nonhuman animals have usually been more preoccupied with the regeneration and repetition of life, whereas men have usually been free to seek ways of transcending life by remodeling, reshaping and recreating the future through technology and symbols (Eckersley, 1992). Also, domination of women and gender inequality are parallels to the environmental destruction (Humphrey, 2002).

Ecofeminists believes men are dominant over women and nature and it is a men's claim that women and nature are inferior to men. Cahill (2002) expresses clearly women's bodies have abilities that men are lacking them. Pregnancy and breastfeeding experience close women to nature and these abilities became the base of oppressing and suffering women by men.

Ecofeminism raised by women who not tolerate the exploitation and oppression of nature and attempt to protect the nature of feminine and motherly feel. They express that environment isn't "gender- free" zones. For example, we speak of "virgin land" the "rape of the wild" and "despoliation of nature", "mother earth" all of which are clearly gendered terms (Barry, 1999). Ecofeminists and deep ecologists have criticized western sciences and the culture of rationalism associated with post-enlightenment western society also (Cudworth, 2003).

Ruether (1975) illustrates several elements that comprise ecofeminism. First, nature has been conceived by the dominant culture as "alien" and separate from humans. This human/nature separation is what feminists call a dualism which is when two concepts are separated and used for analysis. Feminists add the idea that when two concepts such as nature and humans are separated, hierarchy forms and one is given a higher status than another. In this case, humans dominate nature. Second, Ruether's quote suggests that women and nature have traditionally been aligned in terms of symbols and terminology. The popular media have demonstrated this by popularizing the slogan "Love your mother earth." Other examples that engender nature are "raping the land," and "virgin resources." Third, women are already very visible in local grassroots movements and other political activist groups centered on changing policy and rampant consumerism in order to save the environment. Thus, women have already begun to play that major role in the environmental movement that Ruether prophesied. One such role is that of environmentally-conscious consumer (Dobscha, 1993).

In addition, perspectives that considers ecofeminism as a result of the patriarchal oppression, there are perspectives that claims "solutions to ecological problems must include a feminist perspective" (Warren, 1987). From other interpretation ecofeminism is a social movement. As a social movement, ecofeminism can be defined as the community of women that are engaged in restoring and preservative work. Throughout human history, women have been engaged in the environment movement all over the world. Also, ecofeminism is rooted in environmental ethics and feminist ethics (Kronlid, 2003). Banerjeea and Bellb (2007) stated ecofeminism suffers from a tendency to become more an ideological construct than an academic perspective. But despite a recent surge in cross-disciplinary research, especially in critical geography, political ecology, and post-structuralism, questions of gender remain rarely addressed within mainstream environmental social sciences. Given this neglect, they present an alternative conception; eco-gender studies.

This article is worthwhile, because it is based on the theory of ecofeminism; the researchers of this article suppose the fundamental assumptions of ecofeminism are radical, and, as Banerjeea and Bellb (2007) mentioned, suffer from a tendency to become like an ideological construct. In this research, we considered ecofeminism as a 
social and ethical movement and emphasized a feminine solution to environmental problems rather than male oppression against the environment and women.

A review of the experimental background in Iran revealed that little research has been done in this area. For example, Jokar and Mirdamadi (2010) focused on the perspective of female high school students on the issue of environmental protection. They concluded that significant relationships exist between awareness of environmental issues, interest in the environment, attitudes toward environmental protection, participation, the use of instructional videos, and environmental protective behaviors. Rahmani and Majidi (2009) studied the factors affecting women's participation in the urban environment with emphasis on the ecofeminism attitude. Their results showed that, despite women having daily environment-related activities, their attitude toward the environment wasn't more supportive. This research studied women's attitudes and behaviors regardless of the behavior of men. Mohammadiniya (2007) focused on the socioeconomic factors that affect women's environmental performance. Results showed that women are the transfers of environmental literacy and have essential roles in the reform of consumer culture and house management.

\section{Pro- Environmental Behavior}

The term "behavior" is mostly intuitively understood and most psychological and sociological research into behavior has not suggested definitions of the term. However, in the context of the present studies, behavior is any active responding to current environmental issues, believed to be pro-environment of the person performing the response (Eilam, 2012).

Pro-environmental behavior refers to environment-related activities that include a wide range of emotions and desires as well as a willingness to act in a particular way toward the environment. These behaviors may be positive or negative. Efficient use of energy, reducing waste, and using no materials harmful to the environment are examples of pro-environmental behaviors (Aghili et al., 2009). Pro-environmental behavior is described as behaviors that consciously seek to reduce the negative effects of human society and individual actions on the natural and man-made world (Navvah et al., 2011).

Pro-environmental behavior is likely if people feel a moral obligation to perform the behavior (Harland et al, 2007). Environmentally significant behavior can reasonably be defined by its impact: the extent to which it changes the availability of materials or energy from the environment or alters the structure and dynamic of ecosystems or the biosphere itself. Some behavior such as clearing forest or disposing of household waste directly or proximally causes environmental changes. Other behavior is environmentally significant indirectly, by shaping the context in which choices are made that directly cause environmental change (Stern, 2000).

\section{Environmental Attitude}

The term "attitude" has been defined in various ways. Following are three definitions proposed in the literature:

- An enduring combination of motivational, emotional, perceptual and cognitive processes with respect to any aspect of our environment.

- Learned predisposition to respond in a consistently favorable or unfavorable manner with respect to a given object.

- A person's overall evaluation of person (including oneself), objects and issues (Eilam, 2012)

Environmental attitude as an indicator and component of environmentalism refers to the worldview that humans have toward the environment, that environment how be seen and how value attached to it. Also, environmental attitude is generally accepted as responses from the respondent for giving environmental issues such as the pollution and degradation (Tuna, 2004).

Online Psychology Dictionary ${ }^{1}$ (2013) describes an attitude as beliefs of people and society in relation to nature, ecology and issues of the environment and human environmental attitudes looks at how we relate to nature and our surroundings.

Arcury (1990) expressed that knowledge about the environment is assumed to change environmental attitudes, and both environmental knowledge and attitudes are assumed to influence environmental policy. Environmental knowledge is found to be consistently and positively related to environmental attitudes, although the relationship is not especially strong. With the correlation of knowledge and attitudes, the lower level of environmental knowledge has disturbing implications for environmental policy.

\section{HYPOTHESES}

1. Gender has no difference on the average of evaluations for environmental behavior.

2. Gender has no difference on the average of evaluations for attitude to the environment.

1. For more information: http://psychologydictionary.org/environmental-attitudes/

(C) 2017 by Author/s 
Table 1. Frequency of employment status based on gender

\begin{tabular}{lccccccc}
\hline Sex & $\begin{array}{c}\text { Official } \\
\text { Employment }\end{array}$ & $\begin{array}{c}\text { Informal } \\
\text { Empoyment }\end{array}$ & Jobless & Student & Housekeeper & Retired & Total \\
\hline Women & 28 & 41 & 16 & 154 & 96 & 4 & 343 \\
\hline Men & 76 & 110 & 30 & 101 & 1 & 25 & 339 \\
\hline Total & 104 & 151 & 46 & 255 & 97 & 29 & 682 \\
\hline
\end{tabular}

Table 2. Frequency of education based on gender

\begin{tabular}{lccccccc}
\hline Sex & Uneducated & $\begin{array}{c}\text { Primary } \\
\text { School }\end{array}$ & $\begin{array}{c}\text { Secondary } \\
\text { School }\end{array}$ & $\begin{array}{c}\text { High } \\
\text { School }\end{array}$ & Diploma & Graduate & Post-Graduate \\
\hline Women & 0 & 1 & 9 & 81 & 75 & 159 & 14 \\
\hline Men & 3 & 6 & 10 & 88 & 78 & 125 & 33 \\
\hline Total & 3 & 7 & 19 & 169 & 153 & 284 & 47 \\
\hline
\end{tabular}

\section{METHODOLOGY, DATA AND MEASUREMENT}

In Iran, little research has focused on the attitudes or behavior of women and the theory of ecofeminism. This research is a survey based on quantitative methods that investigates environmental attitude as an influential predictor of environmental behaviors among women and men. The estimated population of Tabriz is around 2 million, according to the Iranian Census Bureau. Tabriz is the fourth most populous city in Iran and as a large city has many environmental problems: over-urbanization, air pollution, noise pollution, energy consumption, lack of green space, domestic and industrial wastes, and carbon emissions to name a few. The research population was made up of residents of Tabriz over 15 years of age. The sample size was 682. The multi-stage stratified sampling model was used. Questionnaire data from women and men were used.

Pro-environmental behavior: Pro-environmental behaviors were measured by 24 items in the Likert scale. Items were coded 1 to 6 where $(1)=$ strongly disagree, (2) = disagree, (3) = somewhat disagree, (4) = somewhat agree, $(5)=$ agree, and $(6)=$ strongly agree. The recorded response categories indicated that (1) was the lowest level of pro-environmental behavior and (6) was the highest level of response to pro-environmental behavior. In this research, eight dimensions were constructed for the pro-environmental behavior index. The dimensions of proenvironmental behavior were: efficient consumption of energy, reuse of some goods such as glass or plastic bottles, support of environmental groups, interest in green spaces, avoiding the use of environmentally harmful products, avoiding waste dumping in the environment, waste separation, and use of public transport. The item reliability was .78 , indicating high reliability.

Environmental attitude: Environmental attitude is measured by 15 items in the Likert scale. Items were coded 1 to 6 , where (1) = strongly disagree, (2) = disagree, (3) = somewhat disagree, (4) = somewhat agree, $(5)=$ agree, $(6)$ $=$ strongly agree. The recorded response categories indicated that (1) was the lowest level of pro-environmental attitude and (6) was the highest level of response to a pro-environmental attitude. 15 items of the (NEP) scale developed by Dunlap and Van Liere (2000) were applied to measure a citizen's environmental attitude. The eight items were worded so that agreement indicated a pro-ecological view and the other seven ones were worded so that disagreement indicated a proecological world view. With this commonly used rating scale, respondents were asked to indicate their strength of agreement with each statement. The item's reliability was .64, which indicates acceptable reliability.

\section{Descriptive Results}

In this survey of 682 respondents, 339 were female and 343 were male. In Table 1, the frequency of employment status based on gender is presented. Descriptive results show a high percentage of the women in Tabriz were students. A high percentage of the men in this study had informal employment.

Descriptive results also indicated that a large number of the study men and women are graduated. In Table 2 the results are presented.

The average of women's pro-environmental behavior indicates that women behave ecologically. The women's average was higher than the men's average (112.2>108.8). Moreover, the average of women in efficient consumption of energy, reuse of some goods such as glass bottles, avoiding use of products harmful to the environment, waste separation, avoiding waste dumping in the environment, and using public transport were high. The average of men in support of environmental groups and interest in green spaces was high. The results are demonstrated in Table 3. 
European Journal of Sustainable Development Research, 1:1 (2017), 4

Table 3. The averages of pro-environmental behavior and dimensions

\begin{tabular}{lccc}
\hline Variable and Dimensions & Average of Women & Average of Men & Total Average \\
\hline Pro-environmental Behavior & 112.2 & 108.8 & 113 \\
\hline Efficient consumption of energy & 42.5 & 41.5 & 42 \\
\hline Reuse of some goods such as glass bottles & 21.5 & 20.2 & 20.8 \\
\hline Support of environmental groups & 4.67 & 4.78 & 4.73 \\
\hline Interest in green space & 13.12 & 13.2 & 13.16 \\
\hline Avoiding use of products harmful to the environment & 7.7 & 7.5 & 7.6 \\
\hline Waste separation & 3.5 & 3.1 & 3.3 \\
\hline Avoiding waste dumping in the environment & 10.52 & 10.33 & 10.52 \\
\hline Use of public transportation & 8.4 & 8 & 8.23 \\
\hline
\end{tabular}

Table 4. The averages of environmental attitude

\begin{tabular}{lccc}
\hline Variable and Dimensions & Average of Women & Average of Men & Total Average \\
\hline Environmental attitude & 49.7 & 48.5 & 49.1 \\
\hline Limits of growth & 9.5 & 9.8 & 14.11 \\
\hline antianthropocentrism & 12.3 & 11.8 & 11.6 \\
\hline The possibility of an ecocrisis & 12.6 & 12.7 & 15 \\
\hline The fragility of nature's balance & 2.2 & 2.5 & 14.74 \\
\hline
\end{tabular}

Table 5. The results of t-test for pro-environmental behavior and gender

\begin{tabular}{|c|c|c|c|c|c|}
\hline Variable and Dimensions & Gender & Mean & df & t & Sig. \\
\hline \multirow{2}{*}{ Pro-environmental behavior } & Women & 112.2 & \multirow{2}{*}{680} & \multirow{2}{*}{3.31} & \multirow{2}{*}{.001} \\
\hline & Men & 108.8 & & & \\
\hline \multirow{2}{*}{ Efficient consumption of energy } & Women & 42.5 & \multirow{2}{*}{680} & \multirow{2}{*}{2.03} & \multirow{2}{*}{.042} \\
\hline & Men & 41.5 & & & \\
\hline \multirow{2}{*}{ Use of public transportation } & Women & 8.4 & \multirow{2}{*}{672} & \multirow{2}{*}{1.99} & \multirow{2}{*}{.047} \\
\hline & Men & 8 & & & \\
\hline \multirow{2}{*}{ Waste separation } & Women & 3.5 & \multirow{2}{*}{680} & \multirow{2}{*}{3.31} & \multirow{2}{*}{.001} \\
\hline & Men & 3.1 & & & \\
\hline \multirow{2}{*}{ Reuse of some goods such as glass bottles } & Women & 21.5 & \multirow{2}{*}{680} & \multirow{2}{*}{4.35} & \multirow{2}{*}{.000} \\
\hline & Men & 20.2 & & & \\
\hline \multirow{2}{*}{ Avoiding waste dumping in the environment } & Women & 10.7 & \multirow{2}{*}{679} & \multirow{2}{*}{2.49} & \multirow{2}{*}{.013} \\
\hline & Men & 10.3 & & & \\
\hline \multirow{2}{*}{ Avoiding use of products harmful to the environment } & Women & 7.7 & \multirow{2}{*}{680} & \multirow{2}{*}{.87} & \multirow{2}{*}{.38} \\
\hline & Men & 7.5 & & & \\
\hline \multirow{2}{*}{ Support of environmental groups } & Women & 4.6 & \multirow{2}{*}{680} & \multirow{2}{*}{-.57} & \multirow{2}{*}{.56} \\
\hline & Men & 4.7 & & & \\
\hline \multirow{2}{*}{ Interest in green space } & Women & 13.12 & \multirow{2}{*}{680} & \multirow{2}{*}{-.33} & \multirow{2}{*}{.74} \\
\hline & Men & 13.2 & & & \\
\hline
\end{tabular}

The averages of environmental attitude indicated women consider the environment in a more supportive manner, but the average of men was lower, indicating that men care less about the environment (49.7 $>48.5)$. Furthermore, the average of women in antianthropocentrism was higher than that of men, but the average of men in limits of growth, possibility of an ecocrisis, and fragility of nature's balance was high.

\section{Hypotheses Tests}

Pro-environmental behavior and gender. The differences in the averages of pro-environmental behavior based on gender were measured by t-test. Results showed a significant difference between the averages of women and men in pro-environmental behavior and a significant difference between the averages of women and men in efficient consumption of energy, using public transport, waste separation, reuse of some goods such as glass bottles, and avoiding waste dumping in the environment. The results showed a significant difference between the averages of pro-environmental behaviors (sig. .001), indicating that women behave more environmentally than men. On the dimensions of pro-environmental behavior, the results indicated a significant difference between the averages of efficient consumption of energy (sig. .04). Women use water, electricity, and gas more carefully. The men's efficient consumption of energy average was lower. The average of women in using public transportation was high. There was also a significant difference in the averages of women and men in using public transportation (sig. .04). It could be because of the cultural and economic conditions of women in economic properties in Iran. In waste separation, there was a significant difference between women and men (sig. .001). Women pay more attention to 
Table 6. The Results of T-test for Environmental Attitude and Gender

\begin{tabular}{|c|c|c|c|c|c|}
\hline Dependent variable & Gender & Mean & df & $\mathrm{t}$ & Sig. \\
\hline \multirow{2}{*}{ Environmental attitude } & Women & 49.7 & \multirow{2}{*}{679} & \multirow{2}{*}{2.7} & \multirow{2}{*}{.007} \\
\hline & Men & 48.5 & & & \\
\hline \multirow{2}{*}{ Limits of growth } & Women & 9.5 & \multirow{2}{*}{679} & \multirow{2}{*}{-1.8} & \multirow{2}{*}{.07} \\
\hline & Men & 9.8 & & & \\
\hline \multirow{2}{*}{ Antianthropocentrism } & Women & 12.3 & \multirow{2}{*}{677} & \multirow{2}{*}{2.4} & \multirow{2}{*}{.03} \\
\hline & Men & 11.8 & & & \\
\hline \multirow{2}{*}{ The possibility of an ecocrisis } & Women & 12.6 & \multirow{2}{*}{679} & \multirow{2}{*}{-0.4} & \multirow{2}{*}{.61} \\
\hline & Men & 12.7 & & & \\
\hline \multirow{2}{*}{ The fragility of nature's balance } & Women & 2.2 & \multirow{2}{*}{680} & \multirow{2}{*}{0.3} & \multirow{2}{*}{.72} \\
\hline & Men & 2.5 & & & \\
\hline
\end{tabular}

waste separation and the reuse of some goods such as glass bottles (sig. .001). Women also avoid dumping waste on the environment. In Table 5 these results are demonstrated.

Environmental attitude and gender. The differences between averages of environmental attitude based on gender were measured by t-test, and the results are presented in Table 6 . The results showed a significant difference between women's and men's attitudes toward the environment (sig. 0.007). The average of women was 49.7 and men's average was 48.5. Women believe that plants and animals have as much right as humans to exist, and humans have no right to undermine natural resources or modify the natural environment to suit their needs.

\section{CONCLUSION}

Ecofeminists believe that women play an essential role in the protection of the environment, because women understand nature, and both women and nature are dominated by men. The responsibilities for environmental destruction lie with men. According to Fathi Avjargah and Farmihani Farahani (2003), women are the main group to transfer eco-literacy and manage household consumption. Vandana Shiva considered environmental problems and crises and concluded that humans have just one way to save the environment and nature; that is to retrieve feminine principles and values such as respect for nature. No matter whether it is man or woman or whether they live in the north or the south; humans have just one way (Gare, 1995).

The results of this research suggested that women pay more attention to the environment in attitude and behavior, and the theory of ecofeminism was confirmed. Women care about energy consumption, using public transportation, the reuse of some goods, waste separation, and avoiding waste dumping in the environment. In contrast, these actions have less importance for men. The results also show that the attitudes of women are more supportive than men's attitudes. A significant difference was seen between women's and men's attitudes toward the environment (sig. 0.007). The average of women's antianthropocentrism attitude is also higher than men's; women believe that plants and animals have as much right as humans to exist, and that humans do not have the right to undermine natural resources or modify the natural environment to suit their needs.

These results are compatible with the theory of ecofeminism. We also conclude that women's environmental attitudes and behavior are friendly and respectable. This result proposes the empowerment of women in environmental issues and problems and that home and family be considered the core of environmental education. In the contemporary world, urbanization is growing, and houses are becoming smaller; hence consumption management in households has major importance, and women are the key managers of households. Destruction of the environment and pollution in nature occur because of providing for human needs. Products and goods are taken into houses, and some of the environmental problems start from there. Women manage energy consumption at home, separate and reduce waste, create green space, and decorate their homes with plants and flowers. They also control unnecessary consumption and educate their children about the environment, and so some environmental solutions can be started from the home.

Results are showing differences between female and male behaviors. Respondent women acted in favor of protecting environment with efficient consumption of energy. They are aware energy will end soon. Moreover, reduces cost of energy is important factor in efficient consumption. Women in this research responded that they have deep and particular understanding of value of nature. Reuse of some goods such as glass bottles shows that women do not like to produce waste and start with recycle function at home. Waste separation facilitates recycling and avoiding waste dumping in the environment have shown women to pay attention to environment and nature and they feel really close with the nature.

We could improve environmental behavior using this study in the following ways: waste separation from origin and recycling of waste can be disposed excess of natural resources and reduce risks. Women can decorate their homes with flowers and plants and make more Green space available. Also, women are able to give their kids a 
green-based education. Women could do waste separation at home and produce less waste as much as possible. Women could manage water, electricity and gas consumption in a very efficient manner as well.

\section{REFERENCES}

Aghili, S.M., Khoshfar, G.H., Salehi, S. (2009). Social capital and responsible environmental behavior in north of Iran. Journal of Agricultural Sciences and Natural Resources. Vol XVI. Vol 1 - A. \{Persian\}

Arcury, T.A. (1990). Environmental attitude and environmental knowledge. Human Organization, 49(4), pp. 300304.

Banerjee, D. and Bell, M.M. (2007). Ecogender: Locating Gender in Environmental Social Science. Society \& Natural Resources: An International Journal, 20(1), pp. 3-19.

Barry, J. (1999). Environment and Social Theory. London: Routledge.

Brammer, L. (1998). Ecofeminism, The Environment And Social Movements. New York, NY: Gustavus Adolphus College.

Cahill, M. (2002). The Environment and Social Policy. London and New York: Routledge.

Cudworth, E. (2003). Environment and Society. London and New York: Routledge Publication.

Dobscha, S. (1993). Women and the Environment: Applying Ecofeminism to Environmentally-Related Consumption. Advances in Consumer Research, 20, pp. 36-40.

Dunlap, R., Van Liere, K., Mertig, A. and Emmet Jones, R. (2000). Measuring Endorsement of the New Ecological Paradigm: A Revised NEP Scale. Journal of Social Issues, 56(3), pp. 425-442.

Eckersley, R. (1992). Environmentalism and Political Theory. USA: State University of New York Press.

Eilam, E. and Trop, T. (2012). Environmental Attitude and Environmental Behavior- Which is the Horse and Which is the Cart? Sustainability, 4, pp. 2210-2246.

Fathi Vajargah, K., Farmihani Farahani, M. (2003). Women environmental knowledge for sustainable development. Tehran: Publication of University of Beheshti. \{Persian\}

Gare, A. (1995). Postmodernism and the Environmental Crisis. Routledge Publication.

Harland, P., Staats, H. and Wilke, H.N.A. (2007). Situational and Personality Factors as Direct or Personal Norms Mediated Predictors of Pero-Environmental Behavior: Questions Derived From Norm- Activation Theory. Basic and Applied Social Psychology, 29(4), pp. 323- 334.

Humphrey, C., Lewis, T. and Buttel, F. (2002). Environment, Energy and Society: A New Synthesis. Wadsworth Publication.

Jokar, G. and Mirdamadi, M. (2010). The Perspective of high school girl students in Shiraz to Environmental Protection. Journal of Agricultural Extension and Education, 3(1), pp. 1-13. \{Persian\}

Kronlid, D. (2003). Ecofeminism and Environmental Ethics: An Analysis of Ecofeminist Ethical Theory. Dissertation for the Degree of Doctor of Theology in Ethics. Presented at Uppsala University.

Mohhamadiniya, T. (2007). The study of affecting socioeconomic factors on women's environmental performance: A case study Lipoyi city. MA Thesis. Shiraz University. \{Persian\}

Navvah, A., Forotankiya, Sh. and Porterkaroni, M. (2011). The study of relationship between religious values and environmental behavior (case study in Ahwaz). Journal of Urban Management, 1. \{Persian\}

Rahmani, B. and Majidi, B. (2009). Factors affecting women's participation in the urban environment with emphasis on attitude Ecofeminism. Geography Quarterly Journal, 7, pp. 15-38. \{Persian\}

Ruether, R. (1975). New Woman/New Earth: Sexist Ideologies and Human Liberation. New York, NY: Seabury Press.

Salman, A. (2007). Ecofeminist Movements- from the North to the South. The Pakistan Development Review, 46(4), Part II, pp. 853-864.

Stern, P. (2000). Toward a Coherent Theory of Environmentally Significant Behavior. Journal of Social Issues, 56(3), pp. 407-424.

Tuna, M. (2004). Public Environmental Attitude in Turkey. In: 3rd Global Conference Ecological Justice and Global Citizenship. [online] Australia: Charles Darwin University. Available at: http://www.interdisciplinary.net/ptb/ejgc/ejgc3/tuna\% 20paper

Warren, K. (1991). Introduction to Ecofeminism. American Philosophical Association Newsletter on Feminism and Philosophy.

Warren, K. (1987). Feminism and Ecology: Making Connections. Environmental Ethics, 9(1). 